(3) 3 (3)

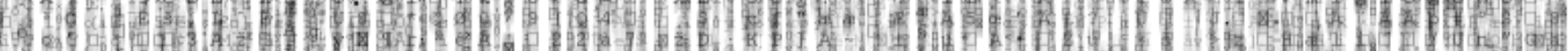
C.5 1.

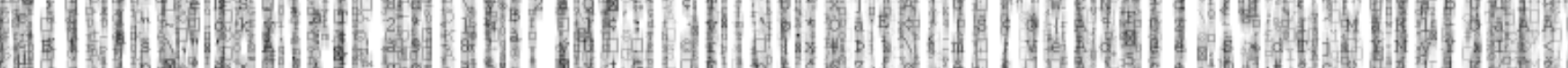

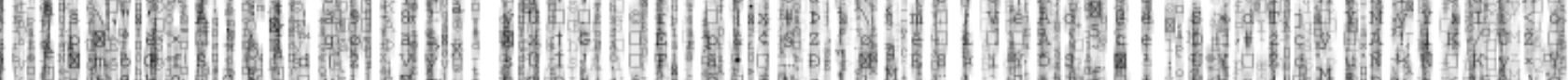
1.6. 1. - exts G. (1) 1. (3)

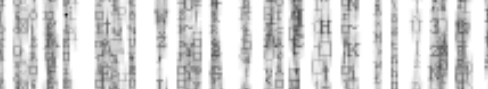
19:

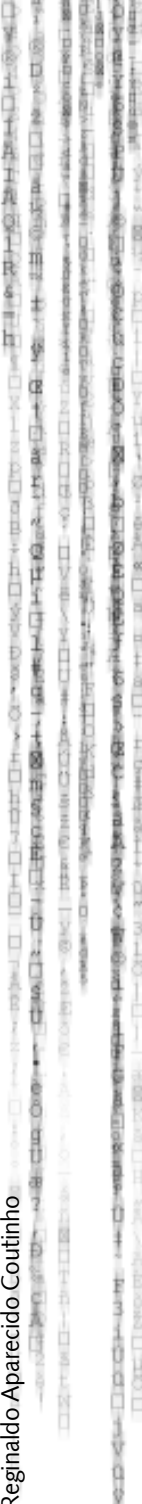

\section{Artigos}

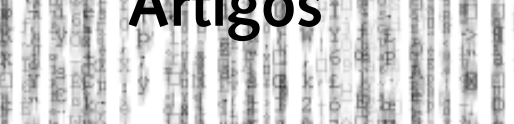

.

18

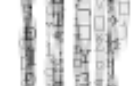

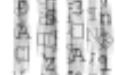

in

a dif

国

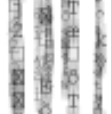

a

10

B. 1

व 7 .

18
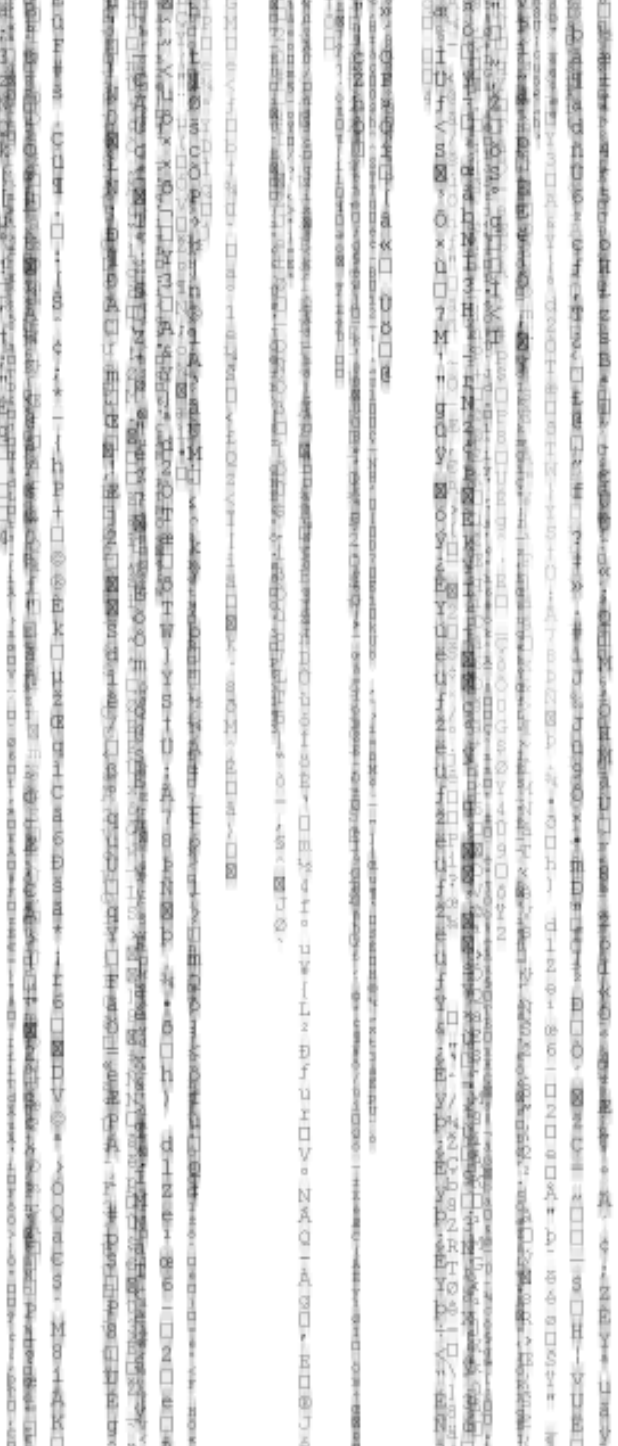

$\frac{1}{2}$ क्ष

in
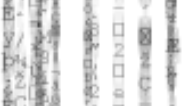

(1)

(1)

(1)

(1)

(1)

(1)

(1)

(1)

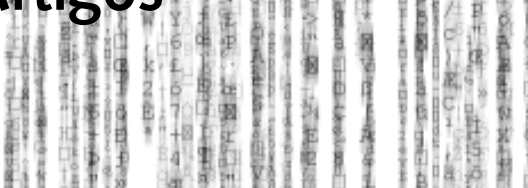

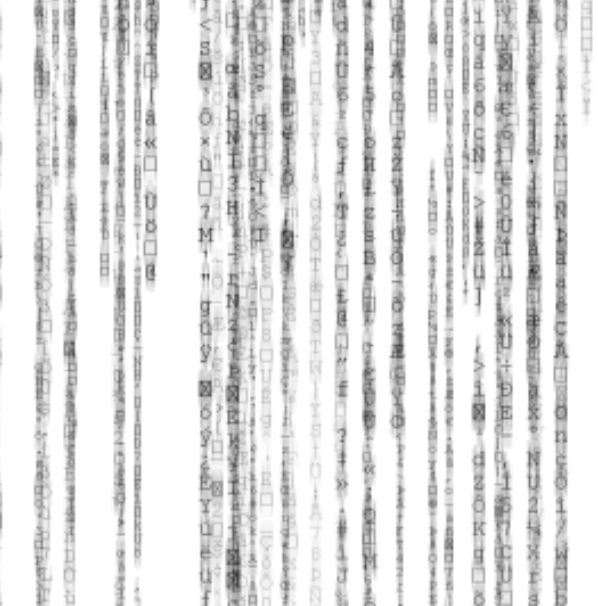

(1) $\mathrm{B}+\mathrm{m}$
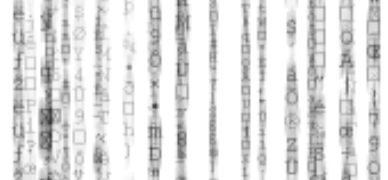

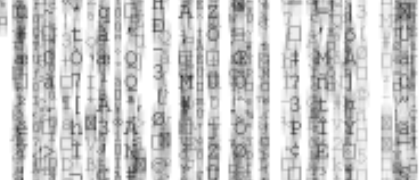

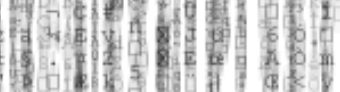

A है eng 1 . 10 of

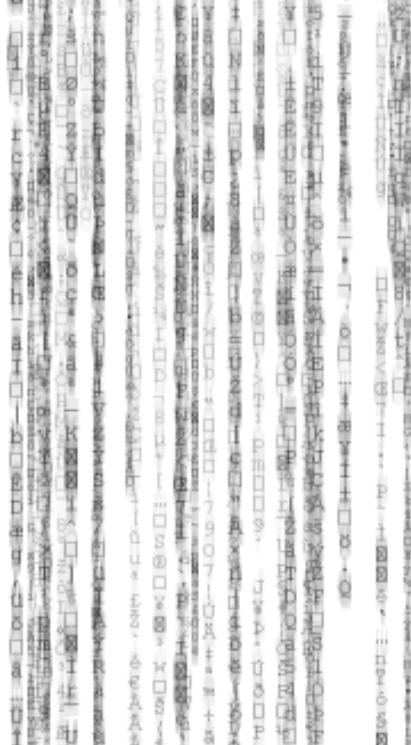

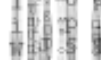

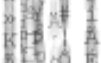

5 踭
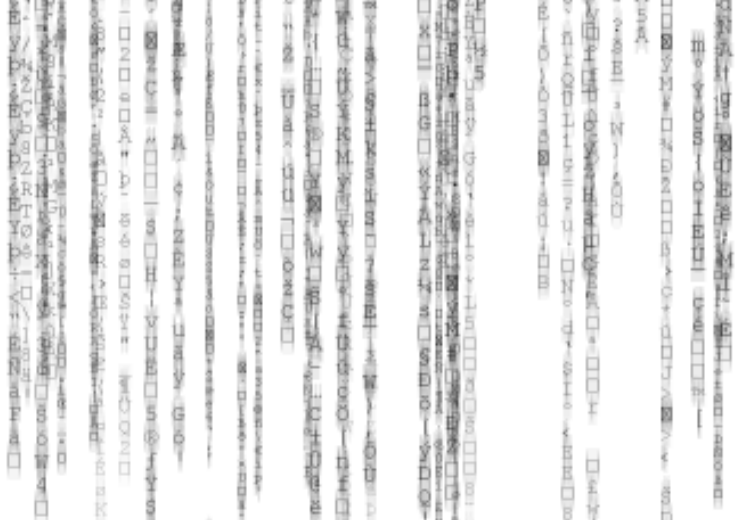

A斯

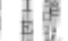




\title{
Imagens possíveis - Karpfen, Carpeaux, Ouro Preto
}

\author{
Eduardo Gomes Silva ${ }^{1}$ \\ Flávio Braune Wiik²
}

\begin{abstract}
ResUMO:
Imagens possíveis... é uma tentativa de demonstrar que outras imagens sobre o ensaísta, crítico literário e ativista político Otto Maria Karpfen/Carpeaux são não somente possíveis como necessárias, haja vista certos 'cenários estáticos' em que o austríaco-brasileiro vem sendo enquadrado. Vida complexa, de rupturas e permanências, Karpfen/Carpeaux buscou o novo no Brasil, embora tenha vivido uma espécie de déjà vu de sua Áustria ocupada (Anschluss) quando do Golpe civil-militar brasileiro de 1964.

Sua dinâmica relação com a cidade mineira de Ouro Preto, traduzida em três diferentes crônicas literárias, escritas antes e depois do Golpe, será o instrumento pelo qual tentaremos construir novas imagens sobre Karpfen/Carpeaux, imprimindo-lhes a devida complexidade.
\end{abstract}

Palavras-chave: Otto Maria Karpfen/Carpeaux. Golpe civili-militar de 1964. Ouro Preto.

\begin{abstract}
:
Possible images ... is an attempt to demonstrate that other images on the essayist, literary critic and political activist Otto Maria Karpfen / Carpeaux are not only possible but necessary; a response to certain 'static scenarios' in which the Austrian-Brazilian is being recently framed. Subject of a complex life, marked by ruptures and continuities, Karpfen / Carpeaux has sought the novelty in Brazil, although he has experienced a sort of déjà vu out of his occupied Austria (Anschluss) when Brazil suffered the civil-military coup in 1964. His dynamic relationship with the Minas Gerais' town of Ouro Preto, translated into three different literary essays written before and after the coup, is the instrument by which we will build new images on Karpfen / Carpeaux, providing them with their deserved complexity
\end{abstract}

Keywords: Otto Maria Karpfen/Carpeaux. Brazilian's civil-military coup. Ouro Preto.

\footnotetext{
1 Mestre em História pela Universidade Federal Fluminense. Doutorando em História Cultural pela Universidade Federal de Santa Catarina, bolsista do Conselho Nacional de Desenvolvimento Científico e Tecnológico (CNPq). Atualmente, desenvolve pesquisa biográfica sobre o austríaco-brasileiro Otto Maria Karpfen/Carpeaux.

2 Doutor em Antropologia pela Universidade de Chicago. Atualmente, é professor Adjunto B junto ao Departamento e ao Programa de Pós-Graduação em Ciências Sociais da Universidade Estadual de Londrina. Ultimamente, tem desenvolvido pesquisa e publicação aproximando História e Antropologia. E-mail: flaviowiik@gmailcom
} Recebido em: 30/03/2014 Aprovado em.30/04/2014 


\section{Preâmbulo - um quadro e um conto ouro-pretense}

Há uma tela de Marcelo Cássio em que a Casa dos Contos de Ouro Preto, antiga Casa dos Contratos, é capciosamente retratada. Não que não estejam lá as linhas sinuosas dos cunhais, as imensas e imponentes aberturas em estilo barroco, as soluções encontradas pelos seus projetistas de modo a vencer as adversidades naturais do terreno (como a imensa arcada que dá estrutura à ponte sobre o rio Tripuí), a linguagem arquitetônica amadurecida e autônoma de um casarão do final dos oitocentos. Tudo isto figura no nanquim e aquarela sobre papel de Cássio, que tampouco se furtou em 'atualizar' seu objeto de modo a incorporar em seus traços as soluções empregadas pela equipe de restauro e manutenção do agora museu e sede do Centro de Estudos do Ciclo do Ouro (Ceco): a cobertura do mirante e o beiral da varanda, por exemplo, destruídos pela ação de quase dois séculos, cintilam feito novos os construídos entre 1782 e 1784 a mando do Contratador de Estradas e Dízimos, João Rodrigues de Macedo.

Se o conluio entre nanquim e aquarela reforça o aspecto colonial de sua imagem, a silhueta de um cipreste de médio porte junto à fachada lateral da Casa nos faz crer que, de fato trata-se do edifício restaurado, pois datação natural (cipreste de médio porte) e datação cronológica (o quadro é de 2011) coincidem. A omissão também se faz presente, e alguém que não conhece aquela construção nunca desconfiaria da ausência, nesta tela, de uma cruz de quase três metros de altura situada exatamente entre o cipreste e a fachada direita da Casa dos Contos. Lacuna que somada ao ângulo pouco provável buscado pelo pintor (defronte de uma das cantarias, tendo a arcada da ponte como primeiro plano e as aberturas da fachada central por destaque - impossível, pois, à observação direta) sugerem um observador espectral, a retratar tal construção 'de cor', sob memória de um tempo em que aquela pesada cruz ainda não existia.

Por privilegiar o monumento a partir de sua imponência externa - João Rodrigues de Macedo era detentor de uma das maiores fortunas do Brasil Colônia -, seria natural tal quadro silenciar frente aos afrescos, aos nichos, aos ósculos, aos sulcos e arcos que conferiam harmonia estilística à Casa dos Contos. A tela de Cássio também silencia frente ao lendário túnel a ligar aquela construção ao Palácio dos Governadores (por onde seria desviado o ouro depositado na Casa, que também era a Casa de Fundição do Ouro e da Moeda), sem contar a enorme senzala, essas nossas seculares Auschwitz, destinada aos escravos 'domésticos'. Pintor-artesão ouro-pretense, Marcelo Cássio parece querer confirmar uma história que corre anos, séculos dizem alguns, em torno daquele casarão. O aspecto soturno, a ausência da cruz e o ângulo improvável presentes nesta sua tela parecem ter a função de plasmar em nanquim e aquarela um estribilho baixinho, algo rouco e sussurrado que vai diminuindo de intensidade até silenciar por completo, nos arredores da Casa dos Contos. Os mais antigos de Ouro Preto chegam a afirmar que esse murmúrio vem com o inverno e acontece às primeiras noites do mês de julho. O que clama ninguém sabe dizer ao certo, mas alguns ouvidos absolutos garantem que esse estribilho é mais ou menos assim: "câncer... câncer de pedra... câncer de pedra compromete as cantarias da casa dos contos... casa dos contratos... câncer... câncer de pedra... casas". 
Figura 1- Sem título (2011) de Marcelo Cássio. 60 × 15 $\mathrm{cm}$. Nanquim e aquarela sobre papel.

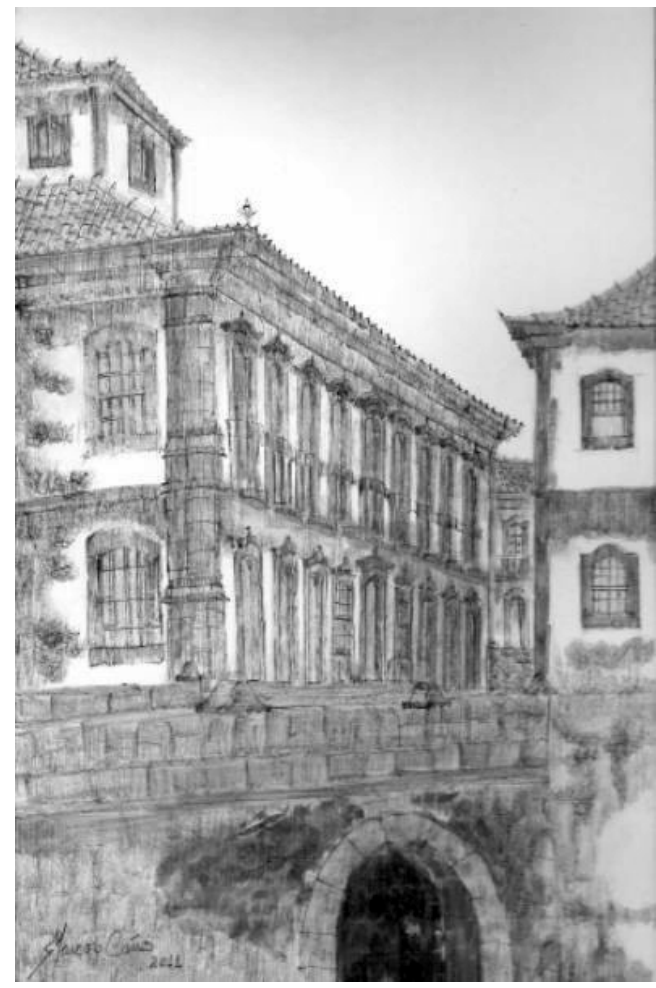

Fonte: Acervo privado de Eduardo Gomes Silva.

Dos muitos mistérios que cercam a Casa dos Contos, talvez aquele que mais estimule a imaginação do povo ouro-pretense é a dúvida de mais de dois séculos envolvendo a morte do poeta Cláudio Manoel da Costa. Um dos capturados pela Coroa Portuguesa em 1789 após a deflagração do movimento que ficaria conhecido como Conjuração Mineira (ou Inconfidência Mineira, segundo os vencedores), seria muito provável que seu destino estivesse associado ao dos muitos revoltosos de posses e/ou status que, uma vez descobertos, foram enviados ao degredo africano. Além do mais, a Coroa já havia imolado o seu cordeiro quando crucificou e esquartejou, meses antes, o alferes que se envolvera em 'negócios de gente graúda'.

O próprio Contratador de Estradas e Dízimos - também ele um conjurado, dada a sua enorme dívida junto ao Erário Real - tivera a sua recém construída Casa dos Contratos ocupada pelas forças da Coroa, a vira ser transformada em quartel e prisão de revoltosos nobres e, por fim, integrada ao Patrimônio Real, mas mesmo assim não perdera sua vida. Já Cláudio Manoel da Costa, também ele oriundo de uma família de poder e influência junto a Lisboa, foi metido numa sala de fundos desta mesma Casa, sala de janelas de ferro e pedras escuras. No dia seguinte, foi encontrado morto. Suicídio ou homicídio?

E quando falamos em estímulo à imaginação, em Ouro Preto ela é vasta. Estava defronte à Casa dos Contos procurando um ângulo aproximado do que teria sido o tomado pelo Marcelo Cássio quando um senhor se aproximou de mim. Sua pele negra contrastava com o alvo terno de linho, um pouco amarrotado, que usava. "Vestido à antiga", pensei comigo. Respondeu-me que sim, gostava de vestir àquela maneira, a despeito do calor que só aumentava em Ouro Preto. Apresentamo-nos - Evaristo era seu nome - e tão logo me disse seu sobrenome - Silva - perguntei qual era a sua opinião a respeito do "mistério Cláudio Manoel da Costa". Riu uma risada larga, quase de escárnio, mas recompôs-se a tempo de dizer, complacentemente: "tem mistério não, seo moço. O poeta foi suicidado!" Rimos juntos. Eu, do seu jeito tipicamente mineiro de resolver o caso. Ele, certamente de mim, da pergunta pomposa para caso tão óbvio. Mas logo o seu cenho enrugou-se, interrompeu o riso para me dizer, agora sério: "mas se o moço quiser ouvir uma história sobre o caso, faço questão de contar. É história do meu povo, ainda do tempo da Vila Rica. Querendo acreditar, acredita, mas não carece não..." Assenti com um meneio e já sentados sobre um banco da praça Senador Rocha Lagoa, sr. 
Evaristo Silva me contou que essa gente "do seu povo" eram os escravos domésticos do Contratador João Rodrigues de Macedo. Era uma história que percorria diversas gerações em sua família, e somente ele conhecia mais de três versões.

Em resumo, tratava-se de um estranho diálogo ouvido pelo único escravo que ainda restava na Casa dos Contratos - naquela altura prestes a se transformar na Casa dos Contos - justamente na noite em que prenderam o poeta Cláudio Manoel da Costa. Diálogo rápido - "mais pra dedo de prosa", me disse o sr. Evaristo - mas importante, porque interrompeu uma "gritaria dos diabos" por parte do poeta. A história do parente distante afirma também que depois da conversa travada a gritaria tornou-se murmúrio, estribilho que varou madrugada adentro... E no dia seguinte, o que todos sabem: Cláudio Manoel da Costa morto. Perguntei pelo conteúdo daquela conversa e o sr. Evaristo respondeu que era ali que as "verdades se separam". Naquele instante o sr. Evaristo levantou quase de pulo, fez pose de ator de teatro e me disse que contaria a versão que ele achava a mais "correta". Disse que ouviu do seu pai que o dedo de prosa ouvido pelo parente antigo tinha sido mais ou menos assim:

" - Cala-te, homem! Aguenta o fardo.

- Quem és tu? Trajes estranhos... olheiras profundas. És morto? Serias eu, morto?

- Deixa de bobagem, poeta. Sou morto, sim, mas não você. Sou um outro.

- Fantasma, então! Ou seria um outro conjurado? Disseram mesmo que havia outros... mas morto? Não! Ao contrário de ti, não morrerei. Tenho um nome, tenho uma família...

- Se fosse você, não confiaria nisto. A esta altura, toda a sua família está sendo executada. - Impossível... impossível!! E nossas influências junto à Corte? Não ousariam matar-me, tampouco aos meus próximos...
- Darão um jeito, caro poeta. Eles sempre dão. Já pensou em suicídio?

- Esconjuro! Nunca cometeria tamanha ofensa.

- Mas eles pensaram...

- Ademais, estou convicto de nossa luta. Há atropelos, como em todas elas, mas creio sim na liberdade desta terra! E vejas, sabes que a esta altura já é 4 de julho. Sabes o que secretamente comemoramos aqui na Colônia, nesta data? Mais um júbilo da Revolução Americana... nosso horizonte e destino! Mas como assim, suicídio?

- É uma astuta solução, poeta. Repetirão comigo. Te matam e forjam seu suicídio. Tudo resolvido! Quanto à "Revolução Americana", bobagem...

- Impossível... impossível!! Louco, louco

é o que és! Impossível. E as Irmandades a que pertenço, como poderiam encomendar minh'alma?

- Encomendarão, fique tranquilo. Tanto a Irmandade de São Miguel e das Almas quanto a Irmandade de Santo Antonio sufragarão mais de 30 missas em nome da sua alma.

- Mas não o fariam se eu me suicidasse...

- O poeta esquece que nesta terra tudo se ajeita. Assim também será comigo: também serei "suicidado" e enterrado dentro do Cemitério Israelita, e não fora dele, que é o destino dos suicidas (por que a cara de espanto? Sou judeu, sim!). Aliás, também será realizada uma grande missa pela minha alma - o que também será uma afronta à versão fraudulenta dos meus algozes.

- Mesmo se assim for, minha luta não teria sido em vão! O exemplo dos Americanos consola-me!

- Bobagem, já disse! Daqui a dez dias iniciará uma revolução maior, dita "francesa". Mudará muita coisa, não o suficiente para impedir a minha morte, a morte do meu povo ou daqueles que lutam contra regimes opressores. Não impedirá regimes opressores, aliás!

- E o que resta disso tudo, então?

- Resta lembrar, sempre. Esquecer, quando necessário... mas isto deixamos pra uma outra conversa.

- Já vais?

- É hora. Em breve os teus verdugos se aproximarão... e olha que ironia: os cadarços do teu calção serão os 'instrumentos do teu suicídio'.

- Louco, louco é o que és. Mas se não fores louco e ainda assim estiveres certo, com que 
nome então registro aquele que por último travei um diálogo...

- Pois não, caro poeta: Herzog é meu nome.

Vladimir Herzog. Mas me conhecerão por Vlado.

- Louco, louco é o que somos..."

Ao narrar as últimas falas, o sr. Evaristo já havia sentado, exausto que estava daquele hercúleo exercício mnemônico. Espanteime não com o diálogo narrado, mas com a precisão com a qual o sr. Evaristo o descrevera. Compartilhei com ele desta minha impressão e mais uma vez ele riu folgado, pra logo dizer: "bobagem, seu moço. A memória sempre falha, ainda mais nessa minha idade. $O$ que disse, nem saberia repetir de novo. Mas assim são as histórias daqui de Vila Rica..."

Figura 2- Foto Casa dos Contos ( $\mathrm{s} / \mathrm{d}$ ) de Jéssica Yumi Hirata.

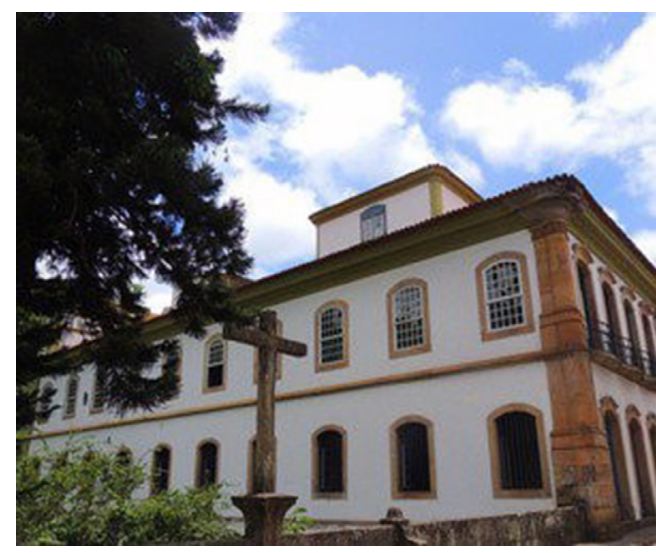

Fonte: OURO PRETO. Prefeitura Municipal (2012).

\section{Karpfen/Carpeaux - os limites de uma história homogênea e linear}

Ao publicar aquele que seria o seu último livro de crítica literária, Vinte e cinco anos de literatura, Otto Maria Carpeaux indicava em "Nota prévia" os caminhos pelos quais seus escritos e sua pessoa trilhariam nos anos subsequentes. A publicação data de 1968 e é toda ela dedicada a Antonio
Houaiss, Carlos Heitor Cony, Ênio Silveira e Mário da Silva Brito. Exatos 30 anos após a anexação austríaca pelo III Reich (Anchulss) e meses antes do chamado 'golpe dentro do golpe' que foi a decretação do Al-5, aquele judeu austríaco nascido Otto Karpfen, transformado em Otto Maria Karpfen após sua conversão ao catolicismo e Otto Maria Carpeaux desde sua inserção no círculo literário brasileiro, iniciava assim aquela coletânea:

\section{Nota prévia}

Um amigo meu calculou que eu tinha publicado na imprensa brasileira, entre 1941 e 1966, mais ou menos 1.500 artigos sobre assuntos literários. Destes, duas centenas foram enfeixados em livros, hoje esgotados e dificilmente acessíveis. E o resto? [...] Fiz uma seleção rigorosa: só escolhi trabalhos que, por este ou aquele motivo, ainda hoje possam inspirar interesse ao círculo de amigos da literatura. Mas já não me incluo nesse círculo. Considero encerrado o ciclo. Minha cabeça e meu coração estão em outra parte. O que me resta, de capacidade de trabalho, pertence ao Brasil e à luta pela libertação do povo brasileiro. Otto Maria Carpeaux ${ }^{3}$ (CARPEAUX, 1968, p. xiv)

Encerrava-se um ciclo, iniciava outro. Mas não datava de 1968 a inserção de Carpeaux neste outro ciclo: sendo ele um dos principais redatores do matutino carioca Correio da Manhã, Carpeaux e alguns outros jornalistas daquele jornal (como Edmundo Muniz e Carlos Heitor Cony) já desafinavam, desde os primeiros dias de abril de 1964, o coro uníssono com o qual a 'grande imprensa' brasileira saudava a então denominada 'Revolução Redentora de 31 de Março'. Quando da publicação de Vinte e cinco

3 Grifos nossos. Esta e as demais citações foram atualizadas conforme o Acordo Ortográfico da Língua Portuguesa de 2008. 
anos..., Carpeaux já havia publicado uma série de artigos contrários ao golpe e aos governos ditatoriais iniciados em 1964"; já havia sido afastado do Correio da Manhã e citado em um Inquérito Policial Militar justamente por sua postura "antirrevolucionária" ${ }^{\text {; }}$ transformado num assíduo colaborador da Revista de Civilização Brasileira (dirigida por Ênio Silveira); e tornado muito próximo de intelectuais que figurariam como fortes opositores ao regime militar - como Florestan Fernandes, Henfil, Leandro Konder e vários outros.

O que faria neste novo ciclo, pouco se sabe. Cony é quem, vez ou outra, menciona o "mambembe não remunerado e estranhíssimo" que representava as "palestras agendadas por diretórios de estudantes e centros de estudos" que ele e Carpeaux proferiam pelos diversos estados do país durante e contra a ditadura. (CONY, 2003). Também Leandro Konder descreve uma dessas atividades 'antirrevolucionárias' compartilhada com Carpeaux. Tratava-se de um debate promovido pela editora Civilização Brasileira na cidade de Juiz de Fora em que Konder, filiado ao Partido Comunista Brasileiro "estava empenhado em fortalecer os movimentos sociais para uma longa luta de resistência antiditatorial", vendo, portanto, "com ceticismo o estado de espírito 'radical' que se manifestava em diversas lideranças e setores expressivos do movimento estudantil." Ainda segundo o relato de Konder, Carpeaux "ardia de impaciência e revolta" e o espírito com que fora ao debate era aquele "disposto a jogar lenha na fogueira". Deixemos Leandro Konder terminar o relato:

4 Coligidos e publicados, também pela Civilização Brasileira, sob os títulos "O Brasil no espelho do mundo" e "A batalha da América Latina", ambos em 1965.

5 Processo SECOM n 36.204, de 23/11/1965. (ARQUIVO NACIONAL, 1996, p. 400).
Quando chegamos a Juiz de Fora, vimos que a promoção da Editora Civilização Brasileira tinha mobilizado muita gente e que os estudantes enchiam o lugar onde íamos debater. Percebi que, entre eles, as tendências de esquerda mais extremadas eram hegemônicas. Os ventos iam soprar mais para o lado do Carpeaux do que para o meu. Tive, então, por um momento, um pensamento mesquinho: "Tomara que a gagueira atrapalhe o discurso dele." Não atrapalhou. Carpeaux, rejuvenescido pela paixão e pela combatividade, comoveu o público com suas palavras candentes, denunciando a ilegitimidade da ditadura militar e conclamando as pessoas à desobediência civil. A estudantada vibrou de entusiasmo. E eu acabei contagiado pelo clima que se criou. Olhando o septuagenário Carpeaux, que lançava as palavras como dardos, que fulminava os reacionários com seu sarcasmo, tive, por um instante,

a impressão de que ele era mais forte do que o general-ditador. (KONDER, 1991, p. 59-64)

Esta e outras histórias compreendem o capítulo intitulado "Otto Maria Carpeaux (1900-1978)" da obra Intelectuais Brasileiros e Marxismo. Através dele, o filósofo Leandro Konder localiza o crítico literário ao lado de outros intelectuais que, no seu entender, estiveram direta ou indiretamente ligados à construção e à divulgação do pensamento marxista no Brasil. Perfazem outros capítulos Oswald de Andrade, Astrojildo Pereira, Caio Prado Junior e até mesmo Sérgio Buarque de Holanda. Publicado por Konder em 1991, este capítulo pode ser considerado um dos primeiros 'balanços de vida e obra' construídos sobre a trajetória de Carpeaux e é possivelmente em contraponto a ele que um outro filósofo, Olavo de Carvalho, dirige estas palavras: 
Não, Carpeaux jamais se tornou marxista. Se no jornalismo político suas posições coincidiam em gênero, número e grau com aquelas defendidas simultaneamente pelo Partido Comunista, só pode ter sido porque, no seu entender nada impedia que um totalitarismo idiota tivesse razão temporariamente contra outro totalitarismo idiota, cabendo apoiar o primeiro pelo simples motivo de ser, na ocasião, o mais fraco perseguido pelo mais forte. (CARVALHO, 1999, p. 21)

Com o título de Introdução a um Exame de Consciência e fôlego que atinge mais de 50 páginas, o principal objetivo do ensaio biográfico de Olavo de Carvalho é apresentar um contraponto à 'imagem de combatente político' com a qual a figura de Carpeaux ficou caracterizada logo após a sua morte. Diante de uma agenda atribulada de atividades antiditatoriais, de difícil refutação, Olavo de Carvalho volta-se à produção literária de Carpeaux para apresentar uma equação que associa a "guinada à esquerda do crítico literário pós-1968" ao seu declínio intelectual (no sentido qualitativo de seus escritos).

A tese não poderia ser mais conservadora, e é construída em torno de uma imagem de Carpeaux associada aos 'grandes espíritos', semideus que teria tudo para ascender ao Olimpo se não tivesse se envolvido com 'questões mesquinhas', com causas menores que acabariam por fazê-lo, Prometeu da modernidade tardia e periférica, cometer o 'maior dos pecados de um intelectual': envolver-se com a política. A antítese é harmoniosa: "À medida que os anos passavam, ele [Carpeaux] se permitiu cada vez mais ser afetado por uma atualidade política mesquinha, deixando dissolver-se em parte, no ambiente de imediatismo brasileiro, a soberana concentração espiritual que Ihe permitira sair ileso das mais deprimentes experiências europeias". (CARVALHO, 1999, p. 17, 19). E a síntese, ao partir de uma elitista concepção de intelectual, só poderia ser esta: "Mas na prática, ao abandonar a missão pedagógica essencial que somente ele [Carpeaux] poderia cumprir, para entregarse a um combate político mais ou menos periférico [...] ele cedeu ao movimento descendente que arrastava a cultura brasileira no rumo da politização imediatista[...]." (CARVALHO, 1999, p. 63).

Além de demonstrar o espírito e parte das razões com os quais Introdução a um Exame de Consciência foi escrito, passagens como esta abundam no ensaio assinado por Carvalho, sempre cioso em encerrar o intelectual em questão na figura do típico scholar europeu em exílio - acima e além de contingências políticas/contextuais e dotado de uma "missão pedagógica." (CARVALHO, 1999, p. 63). É através desta concepção elitista de intelectual que Carvalho se dedicará à apresentação da fase pré-Golpe de 1964 como a mais profícua para os escritos de Carpeaux: "[É entre 1939 e 1964] que datam seus melhores trabalhos, aqueles que conquistaram para ele o mérito de um lugar na história espiritual do mundo, muito além das miudezas políticas do Terceiro Mundo." (CARVALHO, 1999, p. 43).

Nem 'soberana concentração espiritual' tampouco livre de 'miudezas políticas'. O que sabemos acerca da vida de Otto Maria Karpfen no continente Europeu e o que podemos acompanhar através da sua recepção no Brasil demonstram que o passado de Karpfen/Carpeaux, longe de ser 'vencedor' é um 'passado ausente', um passado 'é sido', na rica expressão de Reyes Mate (2011, p. 159). 'Passado vencido', todavia rico e heterogêneo, que esperamos, através deste breve artigo, poder linkar ao nosso presente de modo que lampeje como 
"imagem no agora da cognoscibilidade", como imagem dialética, nas palavras de Walter Benjamin. (BENJAMIN, 2006, p. 515).

Aliás, se aproximarmos as figuras de Otto Maria Karpfen e Walter Benjamin perceberemos que ambos compartilham dados biográficos significativos: os anos que sucederam a ascensão de Hitler ao poder seriam decisivos para ambos. Suas "impressões" de nascimento - seus "mal de arquivo", ser judeus - e suas atuações político-intelectuais no conturbado período pós-1 ${ }^{\text {a }}$ Guerra Mundial os tornaram alvos óbvios da perseguição do III Reich. Suas visões singulares de religião reverberariam em grande parte de suas produções intelectuais. Ambos não seguiram carreira acadêmica. Walter Benjamin, como sabemos, não teve sua tese de livre docência aprovada na Universidade de Frankfurt; Otto Maria Karpfen/Carpeaux tinha como maior obstáculo sua gagueira crônica. A vasta formação humanística de ambos pouco ou nada significava para aqueles que só os viam como mais um a ser executado em nome de uma 'solução final' tão cruenta quanto pretensiosa.

Tais aproximações, embora arbitrárias, não são gratuitas. Tampouco residem nelas o objetivo primeiro deste texto. Sua função é indicar, mesmo que pontualmente, as confluências entre os êxitos e os reveses da vida de Walter Benjamin e a relação dialética destes na sua produção intelectual com o exemplo de Karpfen/Carpeaux. Não pretendemos voltar à tradição saintebeuveniana da 'obra-biografia', já suficiente criticada em Contre Saint-Beuve, de Marcel Proust. Tampouco a inversão do sentido, proposto por Susan Sontag (1986), seja uma solução per se. ${ }^{6}$ A ideia é demonstrar 6 Analisando a obra e a vida de Walter Benjamin no ensaio que dá título ao livro "Sob o signo de saturno", Sontag afirma: "Não se pode interpretar a obra a partir que ambos salvaram-se: as histórias de suas vidas e, sobretudo seus escritos, ainda hoje prestam-se para as mais inúmeras interpretações. Prestam-se para ajudar-nos a suspender a linha contígua entre o passado e o presente; para duvidarmos da história dos vencedores, dos grandes acontecimentos, dos grandes nomes.

Pouco, aliás, se tem escrito sobre a vida de Otto Maria Carpeaux; sobretudo se compararmos à sua vasta produção intelectual. Os exemplos listados acima (Konder e Carvalho), cada qual a sua maneira e segundo seus objetivos, demonstram os limites de uma história contínua, linear que se vem intentando construir acerca da vida e das obras de Carpeaux - história que se pretende "homogênea e vazia", cujos métodos não diferem daquela "empatia com o vencedor", tal qual identificada por Walter Benjamin ao abordar a historiografia historicista. (BENJAMIN apud LÖWI, 2005, p. 70). Em suma, uma história que não dá espaço para as contradições e para a complexidade inerente a toda trajetória de vida.

Diante deste quadro, nos perguntamos como podemos dar o tal "salto sob o céu livre da história", o salto dialético mencionado por Benjamin, a fim de apontar parte dessa complexidade? Das inúmeras possibilidades, traçaremos dois caminhos. O primeiro consiste em contrapormos as imagens idealizadas/ estáticas/monumentais descritas acima à outras imagens, estas prenhes de conflitos e instáveis acerca de Karpfen/Carpeaux. À imagem de um Carpeaux 'revolucionário', temos um Karpfen 'reacionário'. À imagem de um Carpeaux 'livre das miudezas do Terceiro Mundo', um Carpeaux que se manifesta, vai "às vias de fato".

O segundo caminho, um tanto mais

da vida. Mas pode-se, a partir da obra, interpretar a vida." (SONTAG, 1986, p. 87) 
discricionário (e fragmentário), consiste em perceber as sutilezas do olhar de Carpeaux frente a uma cidade que elegera como uma das suas favoritas no Brasil: Ouro Preto. À princípio, e como veremos, tal aproximação é facilmente explicável se pensarmos na figura do exilado que procura na terra adotada as permanências, nachleben ${ }^{7}$ da terra que foi obrigado a deixar. Carpeaux não se livra desta 'sina', embora o que deixou escrito sobre Ouro Preto nos faça perceber que tal aproximação não se esgota aí. Há pelo menos três textos de Carpeaux sobre Ouro Preto; três diferentes textos, aliás. E em todos eles, a relação de Carpeaux com aquela cidade tampouco é estática. Suas distintas experiências e percepções de mundo nos diferentes momentos que esses textos são produzidos/publicados (1958, 1961-1968 e pós-1968) incidem sobre essa relação.

Trilhemos, pois, esses caminhos - que, a exemplo das ladeiras escorregadias de Ouro Preto, estão longe de ser suaves. Como guia (não turístico, mas historiográfico), sugerimos observar o que anunciam e o que silenciam o quadro e o conto ouro-pretenses: as mudanças e das permanências com as quais histórias nacionais e pessoais são construídas; da história escrita e pintada à luz do presente; do múltiplo papel que cabe à imagem nesta escritura (imagem pensada figurativa e metaforicamente).

Antes de Ouro Preto, porém, duas outras imagens nos auxiliam a uma primeira aproximação de Otto Karpfen/Carpeaux. Senão, vejamos:

\section{Sobre duas imagens de Karpfen/Carpeaux}

\section{Cães}

[...] Mas possuo, nesse simbólico e fantástico 7 No sentido que Aby Warburg deu a esta expressão. (apud DIDI-HUBERMAN, 2013). 'grande salão' da minha vida presente, um estranho símbolo, uma estranha lembrança à consciência também: é o meu cão. O pequeno cão preto era um presente dum caro amigo, muito infeliz hoje, lembrança de dias em que o meu 'grande salão' em Viena pareceu muito bem estabilizado. $O$ bichinho era ainda muito jovem, muito pequeno, quando a minha fuga precipitada de Viena me forçou a abandonálo. Neste dia, quando o abandonei, não tive consciência clara. Era um dos quatro dias (e quatro noites), escondido em moradias alheias, a morte sempre presente. [...] Enfim, conseguimos o necessário para fugir. Fomos mendigos, em todos os sentidos, mas enfim no vagão da estrada de ferro, ainda nos subúrbios de Viena, o trem atravessa uma ponte, donde toda a minha cidade natal pode ser abrangida. Era noite e houve só luzes esparsas. Mas eu sabia de cor tudo: sabia, muito perto, o lar perdido, e mais todas as torres e tetos, mais o grande rio, e uma outra ponte; e, do outro lado do Danúbio, a casa onde nasci, o canto onde escondi os brinquedos, o quarto duma adolescência atormentada; e a estátua da deusa nua no recinto da Universidade, as mesas boêmias no sombrio café dos literatos. [...] Já era passada, desde muito, aquela ponte, e o ritmo do trem noturno transformou-se num trem de sombras, trem macabro dos mortos, e trem lúgubre dos vivos que deixei para sempre, transformados eles também em sombras inacessíveis; e ao fim desse sinistro cortejo, trotava, a cabeça baixada como sempre, um pequenino preto cão. $\mathrm{E}$ eu sabia perdida a minha vida.(CP-CDA, 1942a)

\section{Malquerença}

Os escritores Jorge Amado e Otto Maria Carpeaux, inimigos de 15 anos, foram às vias de fato, ontem, após acalorada discussão, à saída do 'Correio da Manhã', onde haviam participado de um almoço em homenagem ao escritor luso Ferreira de Castro. Ao chegar, o autor de 'Gabriela, cravo e canela' cumprimentou os presentes cordialmente, menos o Sr. Carpeaux, que é um dos principais redatores daquele jornal. Entre ambos há uma diferença pessoal que data ainda do período da II Grande Guerra, quando os dois conhecidos homens de letras trocaram impropérios, por motivos de fundas divergências políticas. O tempo não apagou a 
malquerença. E aquele reencontro fez reavivar velhas feridas. O crítico Carpeaux conteve-se, durante o almoço. Mas muito lhe custou, pelo visto, represar a sua indignação pelo fato, de todo imprevisto e que, como era natural, causou mal-estar entre os participantes do almoço. À saída, Carpeaux perdeu a calma e, não resistindo à pressão dos seus melindres, foi tomar satisfações pela ofensa deliberada. Os dois discutiram, trocando expressões violentas, e logo passaram à troca de socos. O incidente não assumiu feição mais séria graças à pronta intervenção dos presentes. (ESCRITORES Jorge Amado... 1959, p.14).

Se tivéssemos que estabelecer um denominador comum entre as duas imagens acima, poderíamos arriscar a faceta humana, demasiada humana, do intelectual que as protagonizou. Separadas cronologicamente por mais de 17 anos, tais imagens revelamnos não o intelectual livre de 'picuinha' e demais 'contingências terrenas', mas sim o de um homem exilado, cujo passado europeu fazia questão de omitir e cuja omissão não o impediu de agir ativamente no cenário intelectual da terra que lhe acolhera. É da equação entre ação e omissão (omissão em narrar sua ativa participação política na Áustria até a anexação nazista) que também é feito o passado de Carpeaux. Passado que demonstra que sua postura intransigente contrária aos governos militares do pós-1964 não teria nascido à influência das 'miudezas políticas do Terceiro Mundo', pois guarda estreita relação com sua posição política préexílio. Passado que ajuda-nos a entender sua recepção por uma determinada parcela da intelectualidade brasileira - longe, pois, de ser resumida à questões pessoais, como sugere a reportagem do jornal O Globo. Quanto mais não seja, tais imagens nos convidam a abandonar a contemplação vertical em direção à torre de marfim e traçarmos uma das muitas possíveis trajetórias de Otto [Maria] Karpfen - Otto Maria Carpeaux.
Nascido na capital austríaca em 1900 (PEREZ, 1968, p. 11-22), Otto Karpfen pertencera a uma família de ascendência judia, por parte de pai, e católica, pelo lado materno. Seus pais, o profissional liberal e judeu Max Karpfen e a senhora proveniente de uma tradicional família católica, Gisela Schmelz Karpfen, gozavam de uma vida sem grandes riquezas materiais, mas plenamente integrada àquela sociedade de caráter tradicional (vivia-se sob o reinado dos Habsburgo desde o século XIII) e ao mesmo passo cada vez mais liberal (sobretudo a partir do século XIX, com a substituição da monarquia absolutista pela monarquia constitucional e parlamentar, que caracterizou o fin-de-siècle naquele império). ${ }^{8}$

Podemos dizer que Otto Karpfen era um legítimo filho da Casa da Áustria, embora pertencente a uma geração cujos novos valores alentados entravam em conflito com essa ascendência - geração representada pelo movimento Jovem Viena' ${ }^{9}$. Tais influências o levariam a obter o título de doutor pela Universidade de Viena (onde frequentou os cursos de Matemática, Física e Química, tendo defendido tese nesta última área), mas também o levariam a aprofundar sua formação na área humanística, através dos estudos de Filosofia e Sociologia, Literatura Comparada e de Política. Sua atuação profissional pósformação foi marcada pelo conturbado período em que a Europa, de uma forma

8 Dentre as obras que melhor pontua tais reformas, destacamos "Viena fin-de-siècle", de Carl Schorske. (SCHORSKE, 1989).

9 No original Jung-Wien, movimento que reunia nomes importantes do campo da poesia e do teatro austríaco/ europeu, tais como: Hugo von Hofmannsthal, Hermann Bahr, Arthur Schnitzler e Stefan Zweig. O principal ponto de atrito de Karpfen a este movimento residia na valorização extremada do esteticismo e do idealismo compartilhada por seus integrantes, o que os afastavam de um engajamento político tomado por Karpfen como premente na Europa do entreguerras (SCHORSKE, 1989). 
geral, e a Mitteleurope ${ }^{10}$, em particular, se encontravam no período posterior à Primeira Guerra Mundial: dissolução dos grandes impérios, liberalismo em crise e ascensão de governos nacionalistas/centralizadores. $\mathrm{O}$ Tratado de St. Germain-en-Laye (assinado pela Áustria em setembro de 1919, que viera à reboque do Tratado de Versalhes), punha fim definitivo a uma 'colcha de retalhos' cuja composição de 17 nacionalidades e 13 idiomas conformavam o Império AustroHúngaro.

Seria nesta jovem república que Otto Maria Karpfen - como assinava seus escritos após sua conversão religiosa, aos 30 anos de idade - atuaria como jornalista político e, uma vez convertido ao catolicismo, como uma espécie de ideólogo do programa político clerical e conservador capitaneado pelo Partido Social Cristão austríaco. Dividida internamente por duas grandes forças políticas (representadas pelo já citado Partido Social Cristão e pelo Partido Social Democrata), além de conviver com o espectro da anexação hitlerista, esta Áustria de Otto Karpfen ainda passaria por um golpe de Estado (o chamado austrofascismo - Ständestaat, no original), iniciado em 1933 com a dissolução do Parlamento e aprofundado em 1934, quando o então chanceler Engelbert Dolfuss cassou os partidos políticos então existentes e passou a governar sem a anuência parlamentar. Paradoxalmente, porquanto fora tomado em oposição à anexação da Áustria pelo III Reich, o Ständestaat acabaria por abrir franco caminho para o Anchulss, finalmente consumado em março de 1938.

Dentre as principais obras escritas por Karpfen neste período, podemos destacar: Wege nach Rom [Caminhos para Roma],

10 Termo que excede a tradução literal, Europa Central, uma vez que compreende uma área "geográfico-cultural e histórica, unificada pela cultura germânica (a Alemanha e o Império Austro-Húngaro)". (LÖWI, 1989, p. 9). assinada por seu nome alemão, Otto Maria Karpfen; e Österreichs europäische Sendung [A missão europeia da Áustria], esta última publicada sob o pseudônimo de Otto Maria Fidelis e considerada a obra-panfleto do Partido Social Cristão. Sem espaço de atuação numa Áustria anexada, Otto Maria Karpfen e sua esposa, Helena Karpfen, rumaram para os países em que o jornalista havia anteriormente mantido contato. A rota exata dos Karpfen até o exílio no Brasil não é consenso entre os poucos trabalhos que abordaram sua história de vida, mas a sua permanência e atuação jornalística em Antuérpia (Bélgica) são dadas como certas, uma vez que há registro de seus artigos no maior jornal belga de língua holandesa, a Gazet van Antwerpen, além de haver fortes indícios de sua colaboração na revista belga católica La Cité Chrétienne - sempre sob o pseudônimo de Otto Maria Fidelis.

As circunstâncias que fizeram do Brasil uma possibilidade de exílio para Otto Maria Karpfen ainda não estão totalmente esclarecidas, mas o certo é que sua condição de judeu apóstata o tornava proscrito das listagens de refugiados elaboradas pela comunidade judaica internacional. Ainda no campo das hipóteses, é possível que os Karpfen tenham se beneficiado do lobby internacional realizado pela Raphaelsverein, uma organização beneficente alemã estabelecida pelo Vaticano com a finalidade de encontrar refúgio para católicos "nãoarianos" alemães. O fato é que sua entrada no Brasil deu-se através de uma articulação envolvendo o Vaticano e o Centro Dom Vital - instituição que, naquele momento (1939), já era dirigida por Alceu Amoroso Lima, embora ainda mantivesse muito do ranço ultramontano dos tempos de seu antigo diretor, Jackson de Figueiredo. Tal trajetória - passado conservador e vínculo inicial no 
Brasil via Centro Dom Vital - em parte explica a antipatia com a qual fora recebido por alguns escritores modernistas nos anos 1940, muitos deles com ligação direta com o Partido Comunista do Brasil (PCB) - como Jorge Amado.

No ano de 1941, já estabelecido no Rio de Janeiro após ter vivido momentos de incertezas desde que chegara ao Brasil, Carpeaux seria introduzido ao círculo intelectual - ao "grande salão", conforme suas palavras - pelo espaço a ele cedido no jornal Correio da Manhã e pelas palavras de Álvaro Lins: “[...] O escritor austríaco, a que estou me referindo, começará a escrever amanhã, no Correio a Manhã, sob o pseudônimo de Otto Maria Carpeaux. Porque conheço este escritor [...] estou certo que a sua atuação, em nossa vida literária, via constituir um acontecimento de excepcional significação." (LINS, 1964, p. 153-160).

Carpeaux foi o pseudônimo que adotou quando passou a atuar regularmente como crítico literário no Correio. Preferiu afrancesar seu nome ao atuar publicamente no Brasil. A despeito da negativa em continuar assinando na mesma língua de seus algozes, conseguiu manter o mesmo significado de seu nome de família: Karpfen, Carpeaux, carpa. Conjecturas nos levam a acreditar que tal pseudônimo deve-se não só à permanência semântica de seu nome em língua francesa como também à coincidência homônima com o renomado pintor e escultor francês do século XIX, Jean-Baptiste Carpeaux - o que, aliás, seria uma estratégia muito bem traçada se pensarmos na francofilia ainda existente na intelectualidade brasileira do início do século $X X$.

Hoje sabemos da importância deste vínculo entre Carpeaux e a crítica literária produzida a partir do Correio da Manhã - sobretudo em um período em que a crítica acadêmica dava seus primeiros passos -, mas esta sua atuação no cenário intelectual brasileiro era percebida pelo próprio Carpeaux como algo mais imanente, ligada à sua própria sobrevivência. Numa carta sua para Carlos Drummond de Andrade, podemos ler:

[...] Depois que uma hora da desgraça [sic] havia destruído toda a minha vida anterior as bases materiais e espirituais da minha existência, conheci dois anos de exílio amargo na Europa, e um ano de extrema miséria e desespero aqui no Brasil. Agora reencontro-me no 'grande salão'. Parece-me um fantasma. Evidentemente não quero aludir às tremendas dificuldades dum naufrago escritor em língua estrangeira. [...] (CPCDA, 1943)

Drummond, aliás, foi um importante contato construído e mantido por então aquele ilustre-desconhecido que havia aportado no Brasil à exemplo de tantos outros exilados (alguns deles já renomados na Europa, como Stefan Zweig). Mas este contato não livraria Carpeaux de suas diatribes com alguns escritores à esquerda daquele período. Nem ele próprio faria questão de livrar-se de tais diatribes e prova disto foi a polêmica travada entre Carpeaux e alguns colaboradores da revista Diretrizes (dentre eles, Samuel Weiner e Carlos Lacerda) em 1943: após um artigo nada amistoso sobre o humanista francês e prêmio Nobel de Literatura, Romain Rolland (CARPEAUX, 1943), Carpeaux fora alvo de um manifesto de repúdio assinado pelos vários escritores e publicado em Diretrizes, o que possivelmente aproximou seu nome à figura de um reacionário. ${ }^{11}$ Dentre as 11 Vale registrar que, embora mantivesse o mesmo nome, nos anos 1940 a revista Diretrizes guardava pouquíssima relação com o momento e com as forças segundo os quais fora criada (criada pelo ideólogo do 
acusações trazidas por este manifesto, constava a 'série de favorecimentos' que Carpeaux vinha recebendo do governo ditatorial de Getúlio Vargas (como o asilo político). Arrastando-se a polêmica para além deste manifesto, outros artigos de repúdio à Carpeaux versavam sobre sua produção intelectual, de características "enciclopédica, eurocêntrica e barroca" - características associadas a um autor "regresso a Hegel, um conformista revestido de inconformismo, uma posição espiritualista de quem se devora a si mesmo", como definia um outro artigo publicado em Diretrizes. (EVARISTO, 1943).

Contribuia para aquela caracterização de Carpeaux a sua recusa em dar informações sobre seu passado austríaco, o qual considerava 'ultrapassado'. Em pelo menos uma significativa situação Otto Karpfen/ Carpeaux deliberadamente omitiu parte de suas atividades políticas na Europa: justamente em seu processo de pedido de naturalização, enviado ao Ministério da Justiça e Relações Interiores (naturalização esta que seria concedida a Carpeaux em 1944). Anos depois, em uma das raras entrevistas que concedera e mesmo já radicado no Brasil há mais de três décadas, ao pressentir tais questionamentos sobre aquele período, Carpeaux asseverou: “Já começa a biografia! Eu não lhe dizia que não quero dar entrevistas biográficas. [...] Não faça a minha biografia!" (JOSÉ, 1976, p. 3-9).

Ainda sobre a polêmica iniciada a partir do artigo sobre Romain Rolland, a consciência do exilado que se sabe estar sob risco uma vez que "tomara posição"12 fica patente numa Estado Novo, Azevedo Amaral, em 1938, tendo por subtítulo Política, Economia, Cultura). Nos anos 1940, década da polêmica em questão, Diretrizes já era dirigida pelo jornalista Samuel Wainer e abrigava grande parte da intelectualidade nacional cujo coro contrário ao Estado Novo aumentava exponencialmente - posição que resultaria no significativo I Congresso Brasileiro de Escritores, em 1945. (WAINER, 1987, p. 49-89).

12 Ou teria tomado partido? Aludimos aqui à reflexão outra carta sua enviada a Drummond, datada de agosto de 1944, onde Carpeaux escreve:

Meu Caro Carlos Drummond, agradeçoIhe profundamente as suas palavras: menos pela boa notícia que me trouxe, porque considero esse 'êxito profissional' como temporário (estou convencido de que a vitoriosa e indisputada campanha de difamação contra mim vai acabar com a minha existência literária, e afinal também com esse emprego); mas pela mentalidade. Nestas semanas, nas quais sou realmente um 'ofendido e humilhado', e além disso um abandonado, foram as primeiras e únicas palavras de amizade que recebi. Agradeço muito. Seu velho, Otto M. Carpeaux. (CP-CDA, 1944)

O emprego que Carpeaux via na iminência de perder era o de diretor da biblioteca da Faculdade Nacional de Filosofia, que de fato deixou em 1945. Àquela época, a direção da Faculdade Nacional de Filosofia estava nas mãos de San Tiago Dantas, mas ao que podemos depreender a partir de uma outra carta de Carpeaux a Drummond (esta de 1942), teria sido através da iniciativa daquela importante figura do Gabinete Capanema (Drummond) que o vienense conseguira tal "colocação":

Prezado Carlos Drummond de Andrade, fui informado pelo professor San Tiago Dantas do seu interesse benevolente com respeito aos meus eventuais serviços na biblioteca da Faculdade Nacional de Filosofia. [...] Constitui-me, após tantas vicissitudes, uma nova existência neste Brasil que será a minha nova pátria. (CPCDA, 1942b)

Mas se mencionamos seu vínculo com que Georges Didi-Huberman estabelece em Cuando las imágenes toman posición. (DIDI-HUBERMAN, 2008). Todavia, reconhecemos que nos falta um estudo mais sistemático para estabelecermos tal distinção no caso de Otto Maria Carpeaux. 
Carlos Drummond de Andrade, o fazemos por dois motivos. O primeiro é apontar o aspecto pragmático daquele início de amizade, a tal 'colocação' - para além das influências literárias que Drummond exercera sobre Carpeaux. O segundo é para fazermos a ponte entre Carpeaux e Minas Gerais. Não Itabira, mas Ouro Preto. E em pelo menos três momentos distintos desta sua "nova pátria".

\section{No meio do caminho, tinha Ouro Preto}

Na mesma obra publicada em 1968 e na qual afirmava que sua "cabeça e coração estavam em outra parte que não no círculo literário", Vinte e cinco anos de literatura, Otto Maria Carpeaux publicou, dentre vários outros, um artigo intitulado Ouro Preto (8 de Julho de 1771). (CARPEAUX, 1968, p. 217-223). Não foi a primeira e tampouco a última vez que escreveria sobre aquela antiga capital das Minas Gerais, pois já o tinha feito em 1958 - Elogio de Ouro Preto (CARPEAUX, 1999 [1958], p. 673-676) - e num outro texto, este não datado e publicado somente postumamente, intitulado Uma visão de Ouro Preto.(CARPEAUX, 2000, p. 13-22).

Em termos cronológicos, depreendese de Ouro Preto (8 de Julho de 1771) a data de sua escrita (seria também a data da primeira publicação?), 1961: “[...] E em 8 de julho de 1711 foi fundada a Vila Rica que comemora, no dia de hoje, seu $250^{\circ}$ aniversário." (CARPEAUX, 1968, p. 218). Mas nestes mesmos termos, o interessante é atentarmos para o resgate anacrônico que Carpeaux lança mão ao publicá-lo. Como já tivemos oportunidade de acompanhar em "Nota Prévia", Ouro Preto (8 de Julho de 1771) e os demais artigos de Vinte e cinco anos de literatura apareciam ali como fruto de uma escolha, de uma "seleção rigorosa" de Carpeaux entre milhares de artigos perdidos no limbo dos suplementos literários e revistas em que o crítico publicara ao longo de três décadas. Uma seleção que, segundo suas palavras, "ainda hoje [1968] possam inspirar interesse ao círculo de amigos da literatura." (CARPEAUX, 1968, p. xiv).

Equação complicada, esta. Ao mesmo círculo de amigos da literatura ao qual diz não mais pertencer é para quem Carpeaux, de alguma forma, publica Ouro Preto (8 de Julho de 1771) e alguns outros artigos. E iniciava político aquele seu Ouro Preto (8 de Julho de 1771), com o crítico indicando, dentre as datas de fundação e de diferentes "descobertas" daquela cidade, a de 1893: "A revolta e a perseguição florianistas no Rio de Janeiro de 1893 obrigaram alguns escritores da época a procurar asilo na então capital mineira, entre eles Bilac e Magalhães de Azeredo [...]." (CARPEAUX, 1968, p. 218). É um dado sui generis, que se destaca, inclusive, no meio das demais datas oficiais da cidade mencionadas por Carpeaux (1698, descoberta pelos bandeirantes; 1711, fundação da Vila Rica).

Em Elogio de Ouro Preto (escrito em 1958), temos o retrato de uma cidade à altura das 'pequenas e admiráveis' cidades europeias: Bruges, Ravenna, Toledo e Assis. À altura e muitas vezes superior, seja pelo "incomparável Aleijadinho", seja pela harmonia entre cidade e natureza: "Em todo caso, a impressão estética de Ouro Preto, a harmonia entre a arte, a paisagem e o que poderíamos chamar historicidade é mais perfeita." (CARPEAUX, 1999 [1958], p. 674). Mas não é um elogio ingênuo, aquele, e Carpeaux não se furta em também apontar o que Ouro Preto fica aquém daquelas outras cidades europeias:

É preciso descontar as falsas admirações [...] as igrejas barrocas de Minas carecem do que é elemento característico do Barroco europeu: não têm cúpulas. [...] Tampouco encontramos em Ouro Preto algo comparável aos mosaicos de San Apollinare Nuovo ou como o túmulo de Galla Placida, em Ravenna; lá é outro o peso das tradições históricas. (CARPEAUX, 1999 [1958], p. 673-674).

Embora reconheça que "certas comparações que não têm cabimento", Elogio de Ouro Preto, todo ele, 
é construído sob o diapasão comparativo. É Carpeaux mesmo quem reconhece: "Tendo visitado as grandes e pequenas cidades de arte, as pequenas e mais admiráveis, sobretudo, Brugues, Ravenna, Toledo e Assis - voltei da Europa, cheio de admiração e saudades de Ouro Preto." (CARPEAUX, 1999 [1958], p. 673). Vale relembrar que este texto foi publicado em 1958, alguns anos depois do primeiro retorno de Carpeaux ao Velho Continente. Ao contrário de muitos exilados da Segunda Guerra Mundial, Carpeaux adotara seu exílio como morada definitiva mesmo após o término do conflito. Data de 1953, portanto, o seu primeiro retorno a Europa - cuja visita não durou mais de seis meses e abrangeu as cidades de Paris, Viena, Madri, Amsterdã e Nápoles.

Mas mesmo este diapasão não resta incólume às demais experiências registradas por Carpeaux nos demais textos. O termo 'cidade morta' associado a Ouro Preto, por exemplo, variaria nos três artigos que então apresentamos. Neste Elogio de Ouro Preto, comparativamente a Toledo ou Brugues, "Ouro Preto, esta sim, é cidade morta", ao que Carpeaux complementa: "Não há, nessa verificação, nada de falso romantismo simbolista à maneira de Rodenbach." (CARPEAUX, 1999 [1958], p. 674) Em Ouro Preto (8 de Julho de 1771) ela já não é mais 'morta'; 'sonolenta', talvez, mas mais viva que muitas outras cidades de interior do Brasil: "De dia, Ouro Preto não é nada morta. Nada de falso romantismo. É sonolenta como todas as pequenas cidades do interior brasileiro; até é mais viva que a maior parte delas, graças aos estudantes da Escola de Minas onde eu tinha e tenho tantos amigos caros." (CARPEAUX, 1968, p. 222). É o olhar de quem já não mais acredita muito em cidades mortas, e lá estão Bruges, Toledo e Ravena para confirmar tal assertiva: "Raramente vi feiras mais vivas que as de sábado em Bruges ou no Zocodover de Toledo, e nunca ouvi barulho mais tumultuoso que o dos italianos em torno da zona dantesta de Ravena." (CARPEAUX, 1968, p. 221). Mas no terceiro texto de Carpeaux sobre Ouro Preto, aquele não publicado em vida e cuja data de produção só podemos conjecturar, Ouro Preto 'renasce' definitivamente, invertendo a relação com suas co-irmãs europeias: "Mas Ouro Preto não é cidade morta, como Bruges, Ravenna ou Toledo." (CARPEAUX, 2000, p. 16).

É notório que nos dois primeiros textos, a referência de 'cidade morta' utilizada por Carpeaux é aquela das cidades cujo passado foram centros de poder/riqueza e que no presente não restam mais que monumentos e outras evidências dos faustos de outrora. Mas em Uma visão de Ouro Preto a referência é outra. Completa Carpeaux:

[Não é cidade morta] é apenas o que sempre foi: uma cidade pobre. No labirinto de ruas, entre as colinas coroadas de igrejas, mora uma população faminta - 'gente abolida', no dizer de Carlos Drummond de Andrade - tão pobre e faminta como em qualquer outra cidadezinha do interior brasileiro e tão oprimida como em qualquer outra parte pela estrutura latifundiária da sociedade dominante." (CARPEAUX, 2000, p. 16) (Grifos nossos)

Revive, Ouro Preto; renasce segundo o olhar de um Carpeaux ainda menos propenso ao Velho Continente. Segundo aquela mesma "Nota Prévia": "O que me resta, de capacidade de trabalho, pertence ao Brasil e à luta pela libertação do povo brasileiro." (CARPEAUX, 1968, p. xiv). Daí podemos supor que Uma visão de Ouro Preto, embora não datado, pertença mesmo a este novo ciclo iniciados por Carpeaux pós-Golpe de 
1964. Há na bibliografia arrolada ao fim deste seu artigo que evidencia datação ${ }^{13}$, mas tal evidencia torna-se prescindível para quem acompanha o restante do texto:

Ouro Preto é, talvez, a cidade mais bela do país. Mas não vamos romantizá-la. Tantas vezes a beleza estética é o reverso da miséria material. Ouro Preto é um pedaço glorioso do passado brasileiro, mas também é um pedaço lamentável do presente. [...] E compreendemos, de repente, que surgiu nessa cidade o revolucionário Tiradentes; e que o Tiradentes, este sim heroico, foi preso, condenado, executado e esquartejado; e que mais outros Tiradentes hão de surgir e vão ter, não se sabe quando, suas estátuas em praça pública. (CARPEAUX, 2000, p. 16).

À exemplo de Walter Benjamin, esse novo olhar 'menos romântico' de Carpeaux volta-se também para o verso da barbárie que acompanha todo esplendor cultural. (BENJAMIN apud LÖWI, 2005, p. 70). E embora devamos desconfiar daquela 'compreensão repentina' da citação em que menciona o velho e os novos Tiradentes ${ }^{14}$, é em Uma visão de Ouro Preto que Carpeaux torna-se mais assertivo, 'pisando em terra firme'. A própria forma como fora escrito sugere isto. Após uma longa digressão sobre a história de Ouro Preto e sobre/sob o olhar com o qual ele a enxerga naquele momento (uma digressão que acompanha a viagem de carro a partir de Belo Horizonte), Carpeaux "aterrissa": "Chegamos. A visão do Itacolomi passou. A visão da Ouro Preto das igrejas passou. Agora estamos pisando a terra firme. Praça Tiradentes em Ouro Preto. Olhamos para frente. Do lado esquerdo, os solares das

13 Trata-se da referência: OLIVEIRA, Franklin de: Morte da memória nacional. 1967". (CARPEAUX, 2000, p. 21). 14 Em Ouro Preto (8 de Julho de 1771) já existia a menção à "gente abolida" e à "presença perpétua da miséria do Brasil rural". (CARPEAUX, 1968, p. 222). grandes famílias ouro-pretenses, hoje extintas [...]. Do lado direito, as miseráveis tavernas em que descansam os tropeiros." (CARPEAUX, 2000, p. 16).

Não há maiores evidências se aquela inclinação verbal, "chegamos", corresponde a uma viagem coletiva a Ouro Preto ou se era resultado de um mero plural majestático empregado por Carpeaux. No início da digressão ela aparece pela primeira vez: “É manhã, cedo. Belo Horizonte ainda dormia, quando partimos [...]."(CARPEAUX, 2000, p. 13). O certo é que em Uma visão de Ouro Preto, a relação estabelecida entre o crítico e aquela cidade é dada a partir da sua experiência pessoal: "para cada um de nós Ouro Preto é uma experiência pessoal, de que pode surgir, em boa hora, uma visão daquele lugar sui generis [...] tão caro também ao brasileiro adotivo e mineiro adotivo que escreve estas linhas: Ille terrarum mihi praeter omnes angulus ridet. ${ }^{15}$ (CARPEAUX, 2000, p. 13). Carpeaux já tinha registrado tal relação em Ouro Preto (8 de Julho de 1771): "Antes, já estive lá três vezes, e assim como todos os outros: em grupo, acompanhado e guiado. Mas em 1961, não. Fui sozinho e fiquei lá, sozinho, na solidão do 'fora da estação turística'". (CARPEAUX, 1968, p. 217).

O diálogo entre esses dois textos - talvez separados por poucos, mas decisivos, anos da vida de Carpeaux - só faz aumentar à medida que vão chegando ao final. E ambos terminam quando Ouro Preto e o próprio Carpeaux "adormecem". Em Ouro Preto (8 de Julho de 1771) o crítico chega a registrar que é à noite que aquela cidade "abre sua alma", embora negue, como já fizera em outra parte daquele texto, a existência de 'fantasmas': "Mas há lugares que é preciso visitar de dia e há lugares que só de noite abrem sua alma. 15 A citação provém de Odes - Livro II, de Horácio, e é traduzida como: "Aquele canto me sorri mais que todos os outros da terra". 
[...] Não saem fantasmas de meia-noite da fechada igreja de São Francisco de Assis." 16 (CARPEAUX, 1968, p. 222-3). Já em Uma visão de Ouro Preto tais 'fantasmas' (Anchulss - Al-5 ?) estão presentes: "Em torno desse teatro há as mais famosas casas assombradas, cada uma com seu espectro particular. Não sei se esses espectros usam, à meia-noite, a magnífica escadaria que leva da rua para o Carmo. Deveriam, pois logo mais em cima estão enterrados." (CARPEAUX, 2000, p. 18).

E se na ausência deles (Ouro Preto 8 de Julho de 1771 - 1961), Otto Maria Carpeaux ainda conseguia adormecer, solitariamente e chamando de casa aquela terra que o havia acolhido ${ }^{17}$, uma vez admitidos (pós-Golpe de 1964), restaria a Carpeaux uma espécie de vigília em nome de uma 'consciência histórica nacional' e de uma liberdade futura que dela proviria: “Apagam-se os ruídos. Na província a gente dorme cedo. [...] Mas é aqui que fica acordada a consciência histórica da nação, do seu grande passado artístico e poético, das suas lutas de libertação, dos seus mártires da liberdade. Pois é a história, é a consciência da história que indica o caminho para o futuro." (CARPEAUX, 2000, p. 19).

\section{Referências}

ARQUIVO NACIONAL. Coordenação de Gestão de Documentos. Relação de processos DSI [Ministério da Justiça]: 1955-1987. Rio de Janeiro, 1996.

BENJAMIN, Walter. Passagens. Tradução de Irene Aron et al. Belo Horizonte: Ed. UFMG, 2006.

CARTA CP-CDA, 21/06/1942a. In: Acervo da Fundação Casa de Rui Barbosa. Arquivos Pessoais

16 A outra citação no mesmo texto é esta: "Vou com o ceticismo saudável de Eduardo Frieiro [...] nunca viu ele nem vi eu fantasmas ali, nem mesmo nas casas assombradas perto do Carmo". (CARPEAUX, 1968, p. 220).

17 A frase que fecha 'Ouro Preto 8 de Julho de 1771' é esta: "Assim adormeci: em Ouro Preto, no Brasil, em casa." (CARPEAUX, 1968, p. 223). de Escritores Brasileiros - APEB. Fundo/Coleção: Otto Maria Carpeaux.

CARTA CP-CDA, 16/07/1942b. In: Acervo da Fundação Casa de Rui Barbosa. Arquivos Pessoais de Escritores Brasileiros - APEB. Fundo/Coleção: Otto Maria Carpeaux.

CARTA CP-CDA, 21/06/1943. In: Acervo da Fundação Casa de Rui Barbosa. Arquivos Pessoais de Escritores Brasileiros - APEB. Fundo/Coleção: Otto Maria Carpeaux.

CARTA CP-CDA, 08/08/1944. In: Acervo da Fundação Casa de Rui Barbosa. Arquivos Pessoais de Escritores Brasileiros - APEB. Fundo/Coleção: Otto Maria Carpeaux.

CARPEAUX, Otto Maria. A morte de Romain Rolland. Revista do Brasil, Rio de Janeiro, dez. 1943.

Vinte e cinco anos de literatura. Rio de Janeiro: Civilização brasileira, 1968.

Elogio de Ouro Preto. In:

Ensaios reunidos - 1942 -1978. Rio de Janeiro: UniverCidade, 1999. p. 673-66. Originalmente publicado em Presenças pelo Instituto Nacional do Livro, 1958.

. Uma visão de Ouro Preto. Belo Horizonte; Rio de Janeiro: Itatiaia, 2000. p. 13-22. Publicação póstuma. Manuscrito original, sem data, de 9 páginas, disponível em OC Pi 09. Acervo da Fundação Casa de Rui Barbosa. Arquivos Pessoais de Escritores Brasileiros.

CARVALHO, Olavo de. Introdução a um exame de consciência. In: CARPEAUX, Otto Maria. Ensaios reunidos - 1942 -1978. Rio de Janeiro: UniverCidade, 1999. p. 15-69.

CONY, Carlos Heitor. O assombro das noites. Folha de São Paulo, São Paulo, 19 nov. 2003.

DIDI-HUBERMAN, Georges. Cuando las imágenes toman posición. Tradução de Inés Bertólo. Madri: A. Machado Libros, 2008.

DIDI-HUBERMAN, Georges. A imagem sobrevivente: história da arte e tempo dos fantasmas segundo Aby Warburg. Rio de Janeiro: Contraponto, 2013.

ESCRITORES Jorge Amado e Otto Maria Carpeaux trocam socos. O Globo. Rio de Janeiro, 10 out.1959. p. 14.

EVARISTO, Manoel. Panorama da crítica. Revista Diretrizes, Rio de Janeiro, ago. 1943. 
JOSÉ - Literatura-crítica e arte. $\mathrm{n}^{\circ}$ 1. Rio de Janeiro: Fontana, 1976. p. 3-9.

KONDER, Leandro. Otto Maria Carpeaux (1900-1978). In: Intelectuais brasileiros e marxismo. Belo Horizonte: Oficina de Livros, 1991. p. 59-64.

LINS, Álvaro. Apresentação de um companheiro europeu em exílio. In: O relógio e o quadrante: ensaios e estudos. Rio de Janeiro: Ed. Civilização Brasileira, 1964. p. 153-160. Originalmente publicado no Correio da Manhã, em 9 abr. 1941.

LÖWI, Michael. Redenção e utopia. O judaísmo libertário na Europa Central: um estudo de afinidade eletiva. Tradução de Paulo Neves. São Paulo: Companhia das Letras, 1989.

LÖWI, Michael. Walter Benjamin: aviso de incêndio: uma leitura das teses "sobre o conceito de história". Tradução de Wanda Nogueira Caldeira Branr. São Paulo: Boitempo, 2005.

MATE, Reyes. Meia-noite na história: comentários às teses de Walter Benjamin sobre o conceito de história. Tradução de Nélio Schneider. São Leopoldo: Ed. Unisinos, 2011.

OURO PRETO. Prefeitura Municipal. Secretaria de Turismo, Indústria e Comercio. Portal de Turismo. Disponível em: < http://www.ouropreto. mg.gov.br/ portaldoturismo/index/index. php?pag $=9 \& \& i d=111>$ Acesso em 05 janeiro de 2012.

PEREZ, Renard. Otto Maria Carpeaux. In: CARPEAUX, Otto Maria. As revoltas modernistas na literatura. Rio de Janeiro: Edições de Ouro, 1968. p. 11-22.

SCHORSKE, Carl. Viena fin-de-siècle: política e cultura. Tradução de Denise Bottmann. São Paulo: Companhia das Letras, 1989.

SONTAG, Susan. Sob o signo de saturno. In: . Sob o signo de saturno. Tradução de Ana Maria Capovilla e Albino Poli Junior. 2. ed. Porto Alegre: L\&PM, 1986. p. 83-95.

WAINER, S. Minha razão de viver: memórias de um repórter. Rio de Janeiro: Record, 1987. p. 49-89. 
